\title{
DERECHO CONSTITUCIONAL ECONÓMICO: ESTABILIDAD PRESUPUESTARIA Y DERECHOS SOCIALES
}

\author{
ELVIRO ARANDA ÁLVAREZ
}


SUMARIO

INTRODUCCIÓN. 1. EL DERECHO CONSTITUCIONAL ECONÓMICO EN LA CONSTITUCIÓN ESPAÑOLA DE 1978: LA AUSENCIA DE UN MODELO ECONÓMICO ACABADO Y CERRADO Y LA DIFUSA MENCIÓN AL EQUILIBRIO PRESUPUESTARIO. 2. EL GASTO PÚBLICO COMO INSTRUMENTO CENTRAL DE UN MODELO DE POLÍTICA ECONÓMICA QUE SE COMPROMETE CON EL ESTADO DEL BIENESTAR. EL ARTÍCULO 31.2 DE LA CE COMO PRINCIPIO DE JUSTICIA MATERIAL EN EL GASTO PÚBLICO. 3. LA ESTABILIDAD PRESUPUESTARIA EN EL DERECHO DE LA UNIÓN EUROPEA. EVOLUCIÓN Y OBJETIVOS. 4. LA TENSIÓN ENTRE DERECHOS ECONÓMICOS Y SOCIALES Y ESTABILIDAD PRESUPUESTARIA. CONCLUSIONES. 


\title{
DERECHO CONSTITUCIONAL ECONÓMICO: ESTABILIDAD PRESUPUESTARIA Y DERECHOS SOCIALES
}

\author{
ELVIRO ARANDA ÁLVAREZ* \\ Catedrático (A) de Derecho Constitucional \\ Universidad Carlos III de Madrid
}

\section{INTRODUCCIÓN}

Desde las posiciones más clásicas del liberalismo, la teoría de la «equivalencia ricardiana» postulaba que no importaba «el método que el gobierno utilice para aumentar el gasto, si emitiendo deuda pública o mediante impuestos, el resultado será el mismo, la demanda se mantendrá sin cambios». Por ese motivo, para David Ricardo, «el mejor gasto público siempre va a ser el que sea equilibrado a los ingresos». En sentido opuesto, en los años treinta del siglo xx, Keynes consideraba que «en momentos de recesión o depresión, el gobierno de una nación tiene el poder y la obligación de ejecutar políticas de expansión del gasto público para compensar la caída de la demanda». Las anteriores afirmaciones acerca del gasto público remiten a dos modelos económicos que, por clásicos y conocidos, no dejan de ser de permanente actualidad y que apelan a dos concepciones ideológicas con las que se ha querido afrontar la crisis financiera que hemos vivido desde $2008^{1}$.

* Universidad Carlos III de Madrid. Facultad de Ciencias Sociales y Jurídicas. Departamento de Derecho Público del Estado. C/ Madrid, 126. 28903 Getafe. Email: elviro.aranda@uc3m.es.

1 Ricardo, D. Principios de economía política y tributación. Estudio preliminar de John Reeder. Edit. Pirámide. Madrid 2003. Pp. 127-130. Smith, A. La riqueza de las naciones. Edit. Alianza Editorial. Economía. Primera reimpresión. Madrid 2002. Pp. 663-804. FrIEdman, M. y FRIEDMAN, R. Libertad de elegir. Hacia un nuevo liberalismo económico. Edit. Ciro Ediciones. Madrid 2011. Pp. 135-168. Hayer, F. Camino de servidumbre. Madrid. Edit. Alianza Editorial. 1978. Pp. 266 
La estabilidad presupuestaria hace referencia a una opción constitucional relativa al manejo del gasto público: el Estado debe garantizar en sus presupuestos que busca el equilibrio entre ingresos y gasto público. Es, por tanto, un concepto que toma partido por una forma concreta de gestionar los recursos públicos. La elaboración del presupuesto, no se olvide, es una de las palancas más importantes que tiene el Estado para su intervención en la economía con el objeto de producir la transformación social que reclama todo Estado social y democrático de Derecho. Más si cabe, cuando tiene entre sus valores superiores la consecución de la libertad y la igualdad entre los individuos y los grupos. Por eso, la ciencia de la Hacienda Pública contemporánea considera que tanto el gasto como los ingresos públicos, en perspectiva macroeconómica, son un instrumento en manos del Estado para satisfacer las necesidades públicas, la redistribución de la riqueza y asegurar el desarrollo y la estabilidad ${ }^{2}$.

Toda Constitución es reflejo de la realidad política existente en la sociedad que la elabora. La Constitución española de 1978 constata muchas de las preocupaciones y necesidades que la España de su tiempo tenía (cuestión territorial, modelo educativo, religión, etc). El paso de cuarenta años sobre nuestro Texto Fundamental ha hecho que muchas de esas preocupaciones hayan cambiado. Incluso que hayan surgido nuevas realidades políticas que han trastocado las soluciones constitucionales dadas hasta ese momento. Es el caso de la incorporación del principio de estabilidad presupuestaria a nuestro derecho constitucional económico que, sin que se nos pueda acusar de exagerados, ha revolucionado jurídicamente la Constitución introduciendo una nueva perspectiva del derecho presupuestario $^{3}$ y, con el mismo nivel de revolución, ha transformado la regula-

y ss. Keynes, J. M. The General theory of employment interest and Money. Edit. Cambridge University Press. For The Royal Economic Society. Reprinted. London 1989. Pp. 245-256. SAmuelson/ Nordhaus. Economía. Duodécima Edición. Madrid 1986. Pp. 415-437. Galbraith, J. K. El nuevo Estado industrial. Edit. Ariel Economía. 7. a edición. Barcelona 1980. Pp. 27-39. Un estudio en profundidad sobre el modelo económico del socialismo real y sus efectos en las políticas sociales puede consultarse en GINER, S. Historia del pensamiento social. Edit. Ariel Sociología. Barcelona 1990. Pp. 501-583. También en Bloch, E. Derecho natural y dignidad humana. Edit. Aguilar. Madrid 1980. Pp. 156-183.

2 Sainz de Bujanda, F. Lecciones de Derecho Financiero. Edit. Facultad de Derecho de la Universidad Complutense. Madrid 1979. Pp. 61-75. Bayona de Perogordo, J. J. y Soler Roch, M. T. Compendio de Derecho Financiero. Edit. Librería Compás. Alicante 1991. Pp. 165-176. LASARTE ÁlvEREZ, J. «El equilibrio presupuestario ante el ordenamiento jurídico». En la obra de AA. VV. El marco jurídico-financiero del sector público: perspectivas de reforma. IX Jornadas de control financiero. Ministerio de Economía y Hacienda. Madrid 1986. Pp. 197 y ss.

${ }^{3}$ La Ley Orgánica 2/2012, de 27 de abril, de Estabilidad Presupuestaria y Sostenibilidad Financiera recoge en su artículo 15 la necesidad del Establecimiento de los objetivos de estabilidad presupuestaria y de deuda pública para el conjunto de Administraciones Públicas. Objetivos que se han de programar de acuerdo con Sistema Europeo de Cuentas Nacionales y Regionales. También se ha establecer el 
ción económica y su incidencia en los derechos económicos y sociales. Por este motivo, cuarenta años después, parece oportuno en un trabajo de conmemoración, retomar la discusión sobre el equilibrio presupuestario en el marco de la «Constitución económica» y sus implicaciones en los derechos económicos y sociales. No es tarea fácil. Ojalá que, al menos, seamos capaces de mostrar los cambios producidos y algunas de las incertidumbres que se vislumbran.

En la tradición constitucional española no había precepto alguno que remitiera a algo parecido al objetivo de equilibrio presupuestario. Por otro lado, el contexto político de la Transición, como veremos más adelante, tampoco era propicio para una norma constitucional de esa naturaleza. Por ello, lo más parecido que encontramos en nuestra Carta Magna al equilibrio presupuestario hasta la reforma del artículo 135 de la CE, es el artículo 31.2 CE cuando habla de que se haga una «asignación equitativa de los recursos públicos». Alguna doctrina ha visto en dicho artículo un precedente de la estabilidad presupuestaria, pero la mayoría de la academia hacendística y financiera ha asociado dicho precepto con la necesidad de que los recursos públicos se distribuyan de acuerdo con el principio de igualdad material y con el objeto de hacer efectivos los derechos, en particular, los derechos económicos, sociales y culturales. Con todas las reservas, por tanto, hasta la reforma del artículo $135 \mathrm{CE}$, el artículo 31.2 CE era el precepto central para entender cómo intervenía la Hacienda Pública en la llamada Constitución económica ${ }^{4}$. Se ocupaba de reconocer los principios sobre los que las Administraciones Públicas podían actuar para hacer posible el Estado social: «asignación

objetivo de deuda pública referidos a los tres ejercicios siguientes. Por supuesto, para la fijación de los objetivos de estabilidad presupuestaria y de deuda pública se tendrán en cuenta las recomendaciones y opiniones emitidas por las instituciones de la Unión Europea sobre el Programa de Estabilidad de España o como consecuencia del resto de mecanismos de supervisión europea, y la propuesta de fijación de los objetivos de estabilidad presupuestaria y de deuda pública estará acompañada de un informe en el que se evalúe la situación económica que se prevé para cada uno de los años contemplados en el horizonte temporal de fijación de dichos objetivos. Dicho informe será elaborado por el Ministerio de Economía y Competitividad, previa consulta al Banco de España, y teniendo en cuenta las previsiones del Banco Central Europeo y de la Comisión Europea. Todo ello se remite a las Cortes Generales para su aprobación o rechazo. En el caso de ser rechazado el Gobierno debe presentar otros objetivos que se han de debatir en un plazo máximo de un mes. Finalmente, aprobados los objetivos de estabilidad presupuestaria y de deuda pública por las Cortes Generales, la elaboración de los proyectos de Presupuesto de las Administraciones Públicas habrán de acomodarse a dichos objetivos.

${ }^{4}$ Que no hubiera un precepto constitucional que hiciera mención expresa a la estabilidad presupuestaria no quiere decir que España, en el marco de dicho principio aprobado por el Derecho europeo no lo incorporase a su legislación. Así fue integrado a nuestro derecho por primera vez en la Ley 18/2001, de 12 de diciembre y en la Ley Orgánica 5/2001, de 13 de diciembre, complementaria de la anterior, para poder comprometer a las CC.AA. en el cumplimiento de dicho principio. Más tarde, se aprueba el Real Decreto Legislativo 2/2007, de 28 de diciembre, que además de refundir los textos anteriores flexibiliza el compromiso de las administraciones con la estabilidad. 
equitativa de los recursos» y "programación y ejercicio del presupuesto de acuerdo a criterios de eficiencia y economía».

Como veremos en el epígrafe correspondiente, la interpretación que se hace de este artículo es que tiene como objetivo asegurar la protección de los servicios y recursos públicos que hacen efectivos los derechos sociales. Una asignación equitativa de los recursos públicos que debe ser congruente con los fines de la Constitución económica, que en el Estado social y democrático de Derecho se corresponde con el modelo de economía social de mercado. Un modelo en el que algunos han visto priorizadas las políticas de gasto sobre las de contención y equilibrio presupuestario. Un modelo que por esa deriva entraría en tensión con los principios económicos de la UE, en donde se prioriza la libertad de mercado, el libre comercio y la menor intervención posible de las instituciones públicas —nacionales o comunitarias_ _ en la relaciones económicas. Si, además, a esos principios económicos comunitarios se añaden la crisis económica, la quiebra financiera de algunos Estados de la UE y la necesidad de que las instituciones europeas salieran a su rescate para evitar su hundimiento, se dan las condiciones para que resurgiera una política de limitación del gasto, estabilidad presupuestaria y control de la deuda pública, que podría entrar en colisión con la imperante hasta ese momento en nuestro sistema constitucional.

La crisis económica iniciada en 2008 y, mucho antes, la política monetaria de la UE puesta en marcha con el Tratado de Maastricht (1992), que ha tenido su culminación en el Pacto de Estabilidad, Coordinación y Gobernanza (PECG), pasando por el Tratado de Lisboa (TUE) y su complementario Tratado de Funcionamiento (TFUE), han reverdecido un eterno dilema de la Hacienda Pública mal resuelto en nuestro texto constitucional: ¿cómo conseguimos compaginar gastos e ingresos públicos sin poner en peligro el modelo de Estado y las exigencias que la constitución material reclama? Ante esta cuestión tenemos dos encontrados puntos de vista.

Para unos, entre los que están los defensores de la reforma del artículo 135 de la CE, lo que se pretende es algo tan claro y evidente como que la Hacienda Pública no destruya con la mano del gasto lo que trabajosamente ha conseguido con la de los ingresos. El objetivo último de la estabilidad presupuestaria y la limitación de la deuda pública es que, además de luchar contra el fraude fiscal, la malversación o el despilfarro, se pongan en marcha políticas de gasto público a partir del principio de distribución equitativa y asignación eficiente de los recursos públicos ${ }^{5}$.

5 Rodríguez Bereijo, Á: «Disciplina presupuestaria, crisis económica y reforma constitucional». En la obra de AA. VV. Crisis y Constitución. XIX Jornadas de la Asociación de letrados del Tribunal Constitucional Edit. Centro de Estudios Políticos y Constitucionales. Cuadernos y Debates, núm. 241. Madrid 2015. P. 185. 
Para otros, lo que se pretende con el cumplimiento del principio de estabilidad presupuestaria y limitación de la deuda pública que proclaman los Tratados de la UE y el artículo 135 de la CE, es reducir el margen de discrecionalidad que tiene el Legislador para configurar el Estado de Bienestar y las potestades, también discrecionales, de las Administraciones Públicas para afrontar las consecuencias de la crisis económica sin perder de vista los derechos fundamentales, en particular los de carácter social, tan trabajosamente conquistados en nuestra sociedad ${ }^{6}$.

El objeto de este artículo es tan simple de enunciar como complejo de resolver: se trata de analizar estas dos posiciones «supuestamente» contrapuestas en cuanto a la relación entre estabilidad presupuestaria y desarrollo del Estado del Bienestar —en particular en su afectación al ejercicio de los derechos económicos, sociales y culturales-. Y se pretende hacerlo en el marco de nuestro derecho constitucional económico y las exigencias que impone formar parte de la UE y la Unión Económica y Monetaria (UEM). Evidentemente, la multiplicidad de cuestiones que se deben analizar nos lleva a que muchas de ellas tan solo se dejen apuntadas dando por supuesto que son sobradamente conocidas y que están ampliamente desarrolladas por la correspondiente doctrina.

\section{EL DERECHO CONSTITUCIONAL ECONÓMICO EN EL TEXTO DE 1978: LA AUSENCIA DE UN MODELO ECONÓMICO CERRADO Y ACABADO Y LA DIFUSA MENCIÓN AL EQUILIBRIO PRESUPUESTARIO}

Desde el constitucionalismo clásico, el derecho financiero y la regulación constitucional económica han estado estrechamente unidos; es más, se podría decir que no se entiende uno sin la otra. El derecho a consentir los impuestos por los representantes (no taxition without representation) y el derecho a aprobar los gastos mediante el Presupuesto (the power of the purse) han sido siempre objeto central de la política económica en las constituciones democráticas. Otra cosa es el grado de intervención de los textos constitucionales sobre esas materias.

En el caso español, la doctrina mayoritariamente entiende que en la Constitución del 1978 no existe un modelo económico constitucional cerrado y acaba-

${ }^{6}$ Quadra-Salcedo Fernández del Castillo, T: «Derecho Público tras la crisis económica en el Estado social y democrático: Estado de bienestar y servicios de interés general». En la obra de AA. VV. Crisis y Constitución. XIX Jornadas de la Asociación de letrados del Tribunal Constitucional Edit. Centro de Estudios Políticos y Constitucionales. Cuadernos y Debates, núm. 241. Madrid 2015. Pp. 77-84. 
do. Pero al mismo tiempo, también se reconoce que ello no impide identificar algunos principios básicos del sistema («economía de mercado», «libre comercio», «derecho a la propiedad» o «participación del Estado en la economía») ${ }^{7}$. $Y$ está de acuerdo en que la multiplicidad de artículos y materias con efectos económicos que regula nuestro Texto Fundamental responde a la voluntad de pacto y acuerdo entre modelos claramente encontrados defendidos en el contexto de su discusión y aprobación. Así, Albertí Robira, que durante años y en distintos trabajos, ha estudiado la «constitución económica», concluye que de la regulación constitucional económica se pueden deducir dos ideas básicas:

Primera. La Constitución no ha establecido un modelo económico cerrado y rígido, que se convierta por sí mismo en la medida de valoración de la constitucionalidad de la intervención pública en la economía. Es la tesis de la neutralidad económica de la Constitución, de la que en algunas ocasiones se ha hecho eco el Tribunal Constitucional.

«En la Constitución Española de 1978, a diferencia de lo que solía ocurrir con las Constituciones liberales del siglo XIX y de forma semejante a lo que sucede en más recientes Constituciones europeas, existen varias normas destinadas a proporcionar el marco jurídico fundamental para la estructura y funcionamiento de la actividad económica; el conjunto de todas ellas compone lo que suele denominarse la constitución económica o constitución económica formal. Ese marco implica la existencia de unos principios básicos del orden económico que han de aplicarse con carácter unitario, unicidad que está reiteradamente exigida por la Constitución, cuyo Preámbulo garantiza la existencia de «un orden económico y social justo», y cuyo artículo 2 establece un principio de unidad que se proyecta en la esfera económica por medio de diversos preceptos constitucionales, tales como el 128 entendido en su totalidad, el 131.1, el 139.2 y el 138.2, entre otros. Por otra parte, la Constitución fija una serie de objetivos de carácter económico cuya consecución exige la adopción de

7 García Pelayo, M: «Consideraciones sobre las cláusulas económicas de la Constitución». En Obras Completas. Tomo III. Edit. Centro de Estudios Políticos y Constitucionales. Madrid 2009. Pp. 2851-2874. Aragón Reyes, M: Libertades Económicas y Estado Social. Edit. McGrawHill. Madrid 1995. Pp. 7-12. marTín RETORTILlo, S: Derecho Administrativo Económico. Tomo I. Edit. La Ley. Madrid 1988. Pp. 76 y ss. ARIÑo, G: Economía y Estado. Crisis y reforma del sector público. Edit. Marcial Pons. Madrid 1993. Pp. 100 y ss. Bassols Coma, M: Constitución y Sistema Económico. Edit. Tecnos. Madrid 1985. Pp. 91-101. Madrid, 1988, esp. pp. 91 y ss. Herrero DE MiÑón, M. «La constitución económica: desde la antigüedad a la integración». En la Revista Española de Derecho Constitucional. Núm. 57. Septiembre-diciembre 1999. Pp. 11-32. TorREs DeL Moral, A: Principios de Derecho Constitucional Español. Tomo I. Edit. Servicio de Publicaciones de la Universidad Complutense. 3. ${ }^{a}$ Edición Renovada. Pp. 80-82. Albertí Rovira, E: «La constitución económica de 1978 (Reflexiones sobre la proyección de la Constitución sobre la economía en el XXV Aniversario de la Constitución española. En la Revista Española de Derecho Constitucional. Núm. 71. Mayo-agosto de 2004. Pp. 125-129. 
medidas de política económica aplicables con carácter general a todo el territorio nacional (arts. 40.1, 130.1, 131.1, 138.1)» (STC 1/1982, de 28 de enero. FJ. 1).

De una forma mucho más clara, el Voto Particular de Díez Picazo y otros en la STC 37/1981, de 16 de noviembre, a propósito de la libertad de empresa se pronuncia en los siguientes términos:

«El origen del actual artículo 38 de nuestra Constitución se encuentra en el artículo 32 del Anteproyecto, donde se decía que «se reconoce el derecho a la libre iniciativa económica-privada». En virtud del debate y especialmente de la enmienda del partido mayoritario, según la cual «el Estado reconoce el derecho a la libre iniciativa privada y reconoce un sistema de economía social de mercado», pasó a tener el texto actual. Recordamos todo ello para señalar que el precepto ha tratado y trata de introducir, por lo menos parcialmente, lo que se ha llamado una constitución económica. El concepto de constitución económica designa el marco jurídico fundamental para la estructura y funcionamiento de la actividad económica o, dicho de otro modo, para el orden del proceso económico. En ella se definen el orden económico en sus fundamentos esenciales y se establecen normas que sirvan de parámetros para la acción de los operadores económicos. Así entendida, la constitución económica contenida en la constitución política no garantiza necesariamente un sistema económico ni lo sanciona. Permite el funcionamiento de todos los sistemas que se ajustan a los parámetros y solo excluye aquellos que sean contradictorios con las mismas. Por ello, nos parece que la norma del artículo 38 y la referencia a la libre empresa en el mercado de la economía social de mercado permite un sistema económico de economía plenamente liberal, una economía intervenida y una economía planificada por lo menos a través de una planificación indicativa.»

Segunda. La neutralidad económica no equivale a apertura absoluta de la misma ni a que pueda justificarse con ella cualquier modelo económico. Las normas económicas constitucionales presuponen determinadas opciones ideológicas de carácter económico. En consecuencia, dichas normas establecen exigencias y límites a la actuación de los poderes públicos que favorecen ciertas propuestas y excluyen otras ${ }^{8}$.

«Este Tribunal ha tenido ya, en diversas ocasiones, oportunidad de pronunciarse acerca del significado de la llamada "constitución económica», como conjunto de normas destinadas a proporcionar el marco jurídico fundamental para la estructura y funcionamiento de la actividad económica, resaltando la importancia que, especialmente en Estados como el nuestro de estructura territorial compuesta, adquiere la exigencia de que los principios básicos del orden económico sean unos y los mismos en todo el ámbito nacional, como proyección concreta del más general principio de unidad que el artículo 2 de la

8 Albertí Rovira, E: La constitución económica de 1978, opus cit. Pp. 126-127. 
Constitución consagra (SSTC 1/1982, fundamento jurídico 1. ${ }^{\circ}$; 11/1984, fundamento jurídico 5..$^{\circ}$; 29/1986, fundamento jurídico 4. ${ }^{\circ}$ )». (STC 64/1990, 5 de abril FJ. 3).

En los años ochenta, Bassols Coma ya hacía un detallado estudio sobre las condiciones teóricas, políticas y sociales que llevaron a la (abundante y dispersa) regulación constitucional económica de nuestro texto de 1978. Allí apuntaba como tanto el panorama ideológico-económico que se vivía en esos años con las crisis del Estado del Bienestar de los años 70, cuanto la influencia que los Pactos de la Moncloa tuvieron en la Transición política, fueron determinantes para que nuestro texto constitucional esté repleto de «declaraciones de alto contenido dogmático en el orden económico y social (...) que podrían ser efímeras, o que resultaban hasta cierto punto contradictorias con el propósito de alcanzar una Constitución consensuada» ${ }^{9}$. Es decir, que el «entramado» normativo constitucional económico es, como en tantas otras cuestiones de la Ley Fundamental, resultado de un compromiso entre fuerzas políticas que tenían pretensiones, en algunos casos, bien distintas. Por un lado, estaban los defensores de un modelo liberal que pretendían sustentar sobre el reconocimiento de la economía de mercado, la libertad de empresa y el derecho de propiedad privada. Por otro, los defensores de un modelo socialdemócrata que, sin negar la economía de mercado, ponían el acento en la necesidad de que los poderes públicos participaran en la economía para hacer efectivo el Estado social y la consecución de una sociedad más igualitaria. Incluso, el grupo comunista, en palabras de su portavoz Carrillo Solares, entendía que con la previsión constitucional establecida en el Título VII, que declara que «toda la riqueza del país está subordinada al interés general, completada con la aceptación de la planificación económica y la intención de favorecer el acceso de los trabajadores a la propiedad de los medios de producción y de cambio», podrían gobernar y aplicar su programa político aquéllos que luchan por una sociedad socialista ${ }^{10}$.

La evidencia de lo que estamos diciendo, en cuanto a diversidad de normas económicas en nuestra Constitución, se ha sistematizado en innumerables ocasiones. En un breve resumen, apuntémoslas nuevamente: se ha de empezar por el desiderátum del Prólogo cuando propugna promover el progreso (...) de la economía para asegurar a todos una digna calidad de vida. Al que se debe inmediatamente acompañar la formulación del Estado social y democrático de Derecho en el que mucha de la doctrina ve la traducción constitucional del Estado del Bienestar. A ambos se han de sumar los valores superiores del ordenamiento: libertad, justicia, igualdad y pluralismo político (art. 1.1 CE). A continuación se ha de reflejar la función promocional de los poderes públicos para facilitar la partici-

\footnotetext{
9 Bassols Coma, M: Constitución y Sistema Económico, opus cit., p. 83.

10 Ibidem. P. 89.
} 
pación de todos los ciudadanos en la vida económica (art. 9.2 CE); y, como despliegue de ese modelo de Estado y esos valores y principios se recogen los derechos, deberes y libertades de carácter económico y, en particular, los de naturaleza social: derecho a la educación (art. $27 \mathrm{CE}$ ), sindicación y huelga (art. $28 \mathrm{CE}$ ); justicia tributaria (art. $31 \mathrm{CE}$ ), propiedad privada (art. $33 \mathrm{CE}$ ), trabajo y derechos laborales (arts. 35 y $37 \mathrm{CE}$ ), libertad de empresa (art. $38 \mathrm{CE}$ ) y los principios rectores de la política social y económica (Capítulo III del Títulos I, arts. 39 a 52 CE). Finalmente quedaría el Título VII de la Economía y Hacienda (arts. 128 a $136 \mathrm{CE}$ ).

De lo anterior, como decíamos, la doctrina se ha inclinado por entender que no ha quedado constitucionalizado ningún sistema económico. No obstante, parece bastante evidente que una regulación de esta naturaleza, donde coexiste el reconocimiento del derecho a la propiedad privada y la libertad de empresa junto a la subordinación de toda la riqueza del país al interés general y la posibilidad de que la iniciativa pública intervenga en la economía se ajusta bien a lo que se ha dado en llamar economía social de mercado ${ }^{11}$. Un modelo donde coexisten interrelacionados empresa privada y sector público. Donde el Estado no solo regula el funcionamiento del sistema económico sino que puede participar en sectores productivos con el objeto de mejorar el desarrollo económico y la consecución de empleo, además de jugar un papel central en la redistribución de la renta y la riqueza. En este sentido el Tribunal Constitucional ha considerado que:

«El Estado social y democrático de derecho del artículo 1.1, que informa una serie de disposiciones como el mandato del artículo 9.2, que prescribe a los poderes públicos "promover las condiciones para que la libertad y la igualdad del individuo y de los grupos en que se integra sean reales y efectivas» $y$ «remover los obstáculos que impidan o dificulten su plenitud», y el conjunto de los principios rectores de la política social y económica del Capítulo III del Título I, cuyo «reconocimiento, respeto y protección» informarán «la legislación positiva, la práctica judicial y la actuación de los poderes públicos», según dice el artículo 53.3 de la Constitución, que impide considerar a tales principios como normas sin contenido y que obliga a tenerlos presentes en la interpretación tanto de las restantes normas constitucionales como de las leyes» (STC 19/1982 FJ. 6. ${ }^{\circ}$ ).

En esa línea de no predeterminación de un modelo económico se debe enmarcar que la Constitución tampoco hiciera una referencia expresa a la necesidad de

11 En este sentido, García Pelayo, M: «Consideraciones sobre las cláusulas económicas de la Constitución, op. cit. y Aragón Reyes, M: Libertades Económicas y Estado Social, op. cit., id 1995. P. 9. López Garrido, D. «Apuntes para el estudio de la constitución económica». En la Revista del Centro de Estudios Constitucionales. Núm. 15 Mayo-agosto 1993. Pp. 79-96. 
equilibrio presupuestario como principio inspirador para organizar las finanzas públicas. Pese a ello, lo cierto es que los clásicos de la Hacienda Pública siempre habían sostenido que los gastos y los ingresos son dos caras de una misma moneda y, por tanto, como entendía Rodríguez Bereijo, «entre la vertiente de los ingresos públicos y la vertiente de los gastos públicos existe una relación de funcionalidad, de instrumentalidad, que hace difícil que una pueda ser entendida sin una referencia a lo otra. Jamás el fin del ingreso público podrá pensarse disociado de su distribución y posterior empleo en forma de gasto público» ${ }^{12}$. Alguna doctrina veía en la falta de mención expresa a este principio la determinación del Constituyente para que esta materia quedase a disposición del Legislador y, por tanto, a un criterio de oportunidad política que llevaría a que dicho equilibrio presupuestario, en su vertiente material, pudiera ser ajustado a los diversos factores económicos que concurrieran en cada ejercicio o ciclo económico. Rodríguez Bereijo recuerda que «las preocupaciones de los constituyentes en 1977 en el momento de redactarse la Constitución eran: la «consecución de un Estado de bienestar con amplias prestaciones sociales, presión fiscal elevada, sector público amplio; todo ello en un régimen básico de libertad de empresa y propiedad privada de los medios de producción, pero con muy fuertes sectores públicos» (...); «modernizar a España significaba entre otras cosas, aumentar el gasto público, en cuanto ello implicaba aumentar las inversiones y los servicios públicos y las prestaciones sociales (... $)^{13}$.

Pero aunque es cierto que no existe una mención expresa al principio de equilibrio presupuestario en la Constitución, como podremos comprobar en el siguiente epígrafe, de la lectura concordada de los apartados $1 .^{\circ}$ y $2 .^{\circ}$ del art. 31 CE dedicados a la justicia tributaria y el gasto público se puede colegir cierta

12 Rodríguez Bereijo, Á. Introducción al estudio del Derecho financiero. Edit. Instituto de Estudios Fiscales. Madrid 1976. P. 70.

13 En este asunto Rodríguez Bereijo sigue los planteamientos de García Añoveros que decía «la Constitución española de 1978 no se preocupa tanto de los problemas económicos del Presupuesto como de las característica que le imprime su funcionalidad en la organización política; el Presupuesto es, ante todo, para la Constitución, una piedra de toque de la distribución del poder entre los distintos órganos políticos. Desde el punto de vista de las preocupaciones de los constituyentes, el Presupuesto es cuestión de poder politico $y$ de equilibrio entre poderes, no de equilibrio económico. No bay, por tanto, en la Constitución, prevenciones contra el déficit y no se crean mecanismos constitucionales para controlarlo, no existe mandato alguno que le afecte. En realidad, la trascendencia económica del Presupuesto es cuestión de poder político y equilibrio entre poderes. No es, para la Constitución, de equilibrio económico». García AÑoveros, J: «Presupuesto y gasto público en la Constitución». En la obra de AA. VV. El sistema económico en la Constitución española. Vol. II. Jornadas de Estudios de la Dirección General del Servicio Jurídico del Estado. Ministerio de Justicia. Madrid 1994. Pp. 1646 y ss. Tesis que puede verse también en ANTONAYA SujA, A. L. «Criterios rectores de aplicación del gasto público». En la obra de AA. VV. Hacienda y Constitución. Edit. Instituto de Estudios Fiscales. Madrid. 1979. P. 244-277 y en SAINZ DE Bujanda, F. Notas de Derecho Financiero. Tomo I. Vol. 2. Madrid. Pp. 173 y ss. 
búsqueda de dicho equilibrio. Sin duda, esta situación cambia con la llegada del artículo 135 CE y se refuerza con la obligación derivada del Pacto de Estabilidad, Coordinación y Gobernanza que limita el crecimiento deficitario del gasto público y el endeudamiento público. Planteamiento que ha cambiado por completo la perspectiva del Derecho presupuestario abriéndolo más claramente a su conexión con la evolución de la economía. Hasta tal punto es así, que no han faltado quienes entienden que este nivel de coordinación y disciplina fiscal impuesta a los ordenamientos internos es de tal intensidad que apenas deja margen de maniobra a las Constituciones económicas nacionales y, lo que es peor, ha generado una idea burocrático-contable del gobierno de la economía que resta todo el protagonismo a la dirección política ${ }^{14}$, no solo de los Estados, sino incluso de las propias instituciones de la Unión Europea ${ }^{15}$.

\section{EL GASTO PÚBLICO COMO INSTRUMENTO CENTRAL DE UN MODELO DE POLÍTICA ECONÓMICA QUE SE COMPROMETE CON EL ESTADO DEL BIENESTAR. EL ARTÍCULO 31.2 DE LA CE COMO PRINCIPIO DE JUSTICIA MATERIAL EN EL GASTO PÚBLICO}

En el derecho constitucional económico, el gasto público no es ni una cuestión menor ni un elemento neutral. La asignación de los recursos está indefectiblemente relacionada con políticas públicas que tienen una gran incidencia en la economía del país y que hacen efectivos los derechos y las libertades de los individuos. En particular, las políticas que implementan los derechos sociales. Quizás por ello, como ya hemos señalado, es por lo que la doctrina financiera de nuestro país casi por unanimidad está de acuerdo en que, hasta la reforma del artículo 135 CE, no existía en nuestra tradición constitucional un principio que remitiera a la necesidad de equilibrio presupuestario. Se decía: puesto que éste es

${ }^{14}$ Un buen ejemplo de lo que estamos diciendo es como se trata lo relacionado con la Deuda pública. Según el apartado 2. ${ }^{\circ}$ del artículo 135.3 CE Los créditos para satisfacer los intereses y el capital de la deuda pública de las Administraciones se entenderán siempre incluidos en el estado de gastos de sus presupuestos y su pago gozará de prioridad absoluta. Estos créditos no podrán ser objeto de enmienda o modificación, mientras se ajusten a las condiciones de la ley de emisión. Sobre la relevancia financiera de éste asunto pude consultarse a De la Hucha Celador, F. «La reforma constitucional de la Deuda Pública». En la Revista Española de Derecho Financiero. Núm. 153. 2012. Pp. 25-26.

15 García Roca, J. y Martínez Lago, M. A: Estabilidad presupuestaria y consagración del freno constitucional al endeudamiento. Edit. Civitas. Thomson Reuters. Navarra. 2013. Pp. 58-59. 
un asunto que tiene una incidencia tan importante en la política económica mejor que quede a disposición del legislador ${ }^{16}$.

Por ello, es conveniente empezar analizando las condiciones que ofrece el artículo 31.2 CE para la protección de los derechos económicos y sociales. Como se adelantaba en páginas anteriores, no debemos perder de vista que estamos ante la norma clave en relación con la justicia financiera y, en particular, con la equitativa distribución del gasto público. Rodriguez Bereijo — de quién se dice fue el inspirador de la llamada enmienda Fuentes Quintana, número 674, presentada por la Agrupación Independiente del Senado, para introducir el principio de eficiencia y economía en la asignación del gasto público- apunta que el artículo 31.2 CE introduce «una de las más importantes y profundas innovaciones de nuestra Constitución financiera que no tiene precedentes en el Derecho público constitucional» ${ }^{17}$. Además, recuerda que, en palabras de Fuentes Quintana, la enmienda se justificaba en dos principios fundamentales ${ }^{18}$ :

En primer lugar, un deber de coherencia entre los apartados 1 y 2 del artículo $31 \mathrm{CE}$. Si en el primero se dice que los impuestos han de distribuirse con arreglo al criterio de capacidad económica y el principio de progresividad, lo lógico es que en el campo del gasto — apartado segundo- también impere el principio de progresividad, para lo cual se introduce la idea de que el gasto público realizará una asignación equitativa de los recursos públicos.

En segundo lugar, un principio de transcendencia o, diríamos nosotros, de previsibilidad. Puesto que el Texto Constitucional ya recogía un amplio catálogo de derechos, era evidente que el gasto público tendría que aumentar para poder hacerlos efectivos. Luego, de ser así, lo lógico es que se estableciese una cláusula que reclamase la equidad para que con la mano del gasto no se «dilapidase» lo que trabajosamente se recaudara con la mano de los ingresos.

16 Matínez Lago, M. A. Manual de Derecho Presupuestario. Edit. Colex. Madrid 1992. P. 23-58. Escribano López, F. Presupuesto del Estado y Constitución. Edit. Instituto de Estudios Fiscales. Madrid. 1981. Pp. 231-318. Pascual García, J. Régimen Jurídico del Gasto Público. Edit. Boletín Oficial de Estado. Madrid. 2005. Pp. 117-154.

17 Rodríguez Bereijo, Á. «El sistema tributario en la Constitución» (Los límites del poder tributario en la jurisprudencia del Tribunal Constitucional). En la Revista Española de Derecho Constitucional. Núm. 36. Septiembre-diciembre 1992. P. 55. Bien es cierto que para otros autores eran demasiadas las «esperanzas puestas en una simple declaración jurídica, aún dotada de rango constitucional». PÉrez Royo, F. «La financiación de los servicios públicos. Principios constitucionales sobre el gasto público». En la obra de AA. VV. Gobierno y Administración de la Constitución. Tomo I. Edit. Instituto de Estudios Fiscales. Madrid. 1988. P. 130.

18 Fuentes Quintana, E: Intervención en la Comisión de Constitución del Senado correspondiente al día 29 de agosto de 1978. Diario de Sesiones, núm. 45, p. 1989. 
Rodríguez Bereijo complementa la explicación del artículo 31.2 CE haciendo referencia a que los derechos de los ciudadanos en relación con el gasto público no se refieren tan solo a que su distribución se haga con equidad, sino también a que su programación, su presupuestación y control tenga lugar con arreglo a los principios de economicidad y eficiencia. También en este caso, la idea que sustenta esta regulación es la antes citada: no tendría sentido que se reclame a los ciudadanos que contribuyan progresivamente a sus ingresos a las necesidades públicas y no se requiera a las Administraciones Públicas un gasto con criterios de eficiencia que neutralice las posibilidades de dilapidación de los recursos públicos.

En consecuencia, en primer lugar, el principio de justicia en el gasto público (31.2 CE) lo que hace es complementar el principio de capacidad económica del sistema tributario (art. 31.1 CE) y, con ello, cerrar un modelo financiero para nuestro país donde las dos patas del sistema -ingresos y gastos- están regidas por una misma lógica: la equidad tanto en la contribución fiscal como en la distribución del gasto. Por tanto, como han señalado autores como Aguiar, Rosado y Ruíz Almendral, con las previsiones constitucionales antes citadas «...unas exigencias de cierta estabilidad no parecen, en principio irrazonables. Pues, aunque la inversión pública pueda servir como incentivador de la economía y orientarse, entre otras posibles, a políticas de fomento del empleo y de corrección de las desigualdades, un déficit excesivo y prolongado puede generar efectos perniciosos en el sistema económico que afecten negativamente a las finalidades perseguidas. De acuerdo con lo dicho anteriormente, Aguiar y Rosado, y una vez analizado el artículo 31.2 CE con el resto de preceptos relacionados por la materia, concluyen que «...la necesidad de cierto equilibrio o estabilidad presupuestaria no fue absolutamente ajena al constituyente» ${ }^{19}$.

Pero tanto la doctrina tributaria —Zornoza Pérez, Cazorla Prieto, Bayona Perogordo- como alguna jurisprudencia del Tribunal Constitucional -STC 86/1985, de 10 de julio — han hecho durante estos años un gran esfuerzo para elaborar una teoría de la justicia tributaria que, a partir del principio de asignación del gasto público de acuerdo a una distribución equitativa de los recursos públicos, se construya teniendo en cuenta el modelo de Estado y los derechos económicos y sociales que propugna nuestra Carta Mágna ${ }^{20}$. Zornoza Pérez dice que la equitativa distribución del gasto solo se entiende en relación

19 Aguiar De Luque, L. y Rosado Iglesias, G: «La estabilidad presupuestaria y su eventual proyección en el Estado de las Autonomías». En Cuadernos de Derecho Público. Núm. 12. 2012. Pp. 21-27. Ruiz Almendral, V: Estabilidad presupuestaria y gasto público en España. Edit. La Ley. Primera edición 2008. Madrid. P. 147-148.

20 Bayona de Perogordo, J. J. y Soler Roch, M. T. Compendio de Derecho Financiero. Opus cit., Pp. 165-176. Ruiz Almendral, V. y Zornoza Pérez, J. J. «Constitución económica y 
con un gasto justo y, para este autor, dicho gasto cumple el criterio de justicia cuando sirve para hacer efectivos los derechos regulados en las normas constitucionales que consagran los derechos económicos y sociales (v.gr. serían gastos justos los que se hacen para satisfacer el derecho a la educación art. 27 CE; los hechos para garantizar el acceso al derecho al trabajo artículo 35.1 CE o el derecho a la vivienda art. 47 CE). El artículo 31.2 CE junto con el 9.1 CE constituyen el fundamento para que los poderes públicos promuevan programas orientados a conseguir los objetivos sociales que reclama un Estado social y democrático de Derecho (art. 1.1 CE) ${ }^{21}$. Dicho planteamiento ha llevado a alguna doctrina a señalar que el contenido material de la asignación equitativa de los recursos públicos supone ${ }^{22}$ :

- Que queda proscrito todo gasto público que por arbitrario contradiga las aspiraciones sociales y económicas plasmadas en la Constitución. Aquél gasto que favorezca de forma evidente las desigualdades entre ciudadanos y territorios del Estado.

- Que el gasto público se ha de organizar para promover que las condiciones para la libertad y la igualdad del individuo y los grupos en los que se integran sean reales y efectivas (art. 9.2 CE), así como a la aplicación efectiva de los derechos sociales (arts. 27,28 y 39 a $52 \mathrm{CE}$ ).

- La orientación de los servicios públicos que prestan las distintas administraciones se ha de organizar teniendo en cuenta la asignación equitativa de los recursos públicos: de forma que queden por igual a disposición de todos los ciudadanos, sin menoscabo de que en razón del principio de igualdad material se presten para unos ciudadanos en condiciones más favorables e, incluso, gratuitamente.

- Puesto que la distribución equitativa del gasto público está regulada en el artículo 31.2 CE, se encuentra amparado por las previsiones del 53.1 CE, lo que conlleva la vinculatoriedad para todos los poderes públicos, reserva de ley, respeto al contenido esencial y protección jurisdiccional a través del recurso de inconstitucionalidad.

En definitiva, que por mucho que el nuevo artículo 135 CE establezca, como ya veremos, un principio y un mandato a los poderes públicos para garantizar la estabilidad presupuestaria y el control del déficit estructural, no se ha de perder de

Hacienda Pública». En la obra de AA. VV. La Constitución a examen. Un estudio académico 25 años después. Edit. Marcial Pons. Madrid. 2004. Pp. 643-653.

21 Zornoza PÉrez, J. «Hacienda pública, gasto público y derechos económicos y sociales». En la Revista Derecho del Estado. Núm. 10, junio 2001. Pp. 32-37.

22 Vid. por todos, Pascual García, J. Régimen Jurídico del Gasto Público. Opus cit. Pp. 132-136. 
vista que también tenemos constitucionalizado el principio de justicia material en el gasto público que actúa como instrumento de tutela y garantía jurídica de los ciudadanos ante las políticas prestacionales de los poderes públicos y garantizando niveles mínimos de prestaciones de bienes y servicios públicos ${ }^{23}$.

En esta situación no quedaría más remedio que dilucidar la solución al dilema entre aquéllos que piensan que «las disponibilidades presupuestarias» $\mathrm{o}$ «lo financieramente posible» puede constituir una restricción (infranqueable jurídicamente) a la efectividad de los derechos constitucionales. Es decir, ¿en qué medida la generalización o universalización de los derechos sociales puede conducir, por la limitación de las «disponibilidades presupuestarias» y la crisis fiscal del Estado, a un nivel de estándar mínimo en la prestación de derechos o, incluso, a su denegación ${ }^{24}$ ? Y la tesis que sostiene que en un Estado social y democrático de Derecho los derechos — más allá de su naturaleza — son pieza cardinal del orden democrático y actúan como límite del poder estatal. Por dicha razón, todos ellos terminan, en el constitucionalismo normativo, siendo «derechos subjetivos» y tienen una proyección objetiva que impregna todo el sistema normativo y la acción de los poderes públicos. De manera que, como ha señalado De la Quadra-Salcedo, «la economía podría llegar a ser una razón más que suficiente para, si se demuestra necesario y se dan las demás condiciones requeridas, ajustar a la baja los derechos sociales. Otra cosa es que los limites del déficit y deuda, se erijan sin más en estabilizadores automáticos de los derechos fundamentales del Capitulo III del Título I de la CE» ${ }^{25}$.

\section{EL PRINCIPIO DE ESTABILIDAD PRESUPUESTARIA COMO DERECHO CONSTITUCIONAL ECONÓMICO DE LA UNIÓN EUROPEA. SU REFORZAMIENTO EN UN CONTEXTO DE CRISIS ECONÓMICA}

Una cuestión previa de gran importancia para el tema que estamos tratando — que solo se va a apuntar, por exceder las pretensiones de este trabajo- es el impacto del principio de primacía del Derecho europeo originario o primario sobre las constituciones nacionales. Como ha señalado la doctrina más autorizada y la jurisprudencia clásica del TJUE en los casos Van Gend E Loos, Costa/Eneel o Sim-

23 Zornoza Pérez, J. Hacienda pública, gasto público..., op. cit. P. 33.

24 Rodríguez Bereijo, A. «Disciplina presupuestaria, crisis económica y reforma constitucional». En la obra de AA. VV. Crisis y Constitución. Asociación de Letrados del Tribunal Constitucional. Edit. Centro de Estudios Políticos y Constitucionales. Madrid 2015. P. 174.

25 Quadra-Salcedo Fernández Del Castillo, T: Derecho Público tras la crisis económica en el Estado social y democrático..., opus cit. P. 132. 
menthal ${ }^{26}$ se debe reconocer la supremacía material de Derecho europeo primario y su carácter vinculante y obligatorio; supremacía material que, para muchos, llega hasta las normas constitucionales domésticas por mucha supremacía formal que las normas constitucionales nacionales presenten ${ }^{27}$. Como ha dicho Muñoz Machado, la integración en la UE en los términos que se establece respecto de la relación entre el Derecho de los Estados y el Derecho de la Unión supone que se ha producido una auténtica mutación constitucional del Derecho interno. La legislación y las politicas legítimas de la Unión cambian la Constitución porque, como antes se ha dicho, se trasladan a las instancias europeas competencias reservadas en aquélla a los poderes internos, transforman las responsabilidades de éstos, se apoyan en regulaciones que afectan a los derechos individuales e, incluso, difunden principios y exigen comportamientos a los Estados miembros que no aparecen expresados en la Constitución ${ }^{28}$. Aunque esta es una realidad que parece asentada doctrinal y jurisprudencialmente, la cuestión es si esas mutaciones constitucionales pueden llegar a transformar las Constituciones de los Estados o, por el contrario, el respeto al principio de identidad nacional (art. 4.2 TUE) tiene que actuar como límite al ejercicio de los poderes de la Unión Europea. Porque de no ser así, y admitiendo la primacía del Derecho europeo sobre las Constituciones nacionales, estaríamos, como apuntó Rubio Llorente, «transfiriendo a las instituciones europeas la potestad de reformar nuestras Constituciones, siempre que, en ejercicio de sus competencias propias, estimen necesario bacerlo» ${ }^{29}$.

26 SSTJUE de 15 de febrero de 1963 (26/1962), Van Gend E Loos; de 15 de julio de 1964 (6/1964), Costa /Enel y 9 de marzo de 1978, (106/1977) Simmenthal.

27 García Roca, J. y Martínez Lago, M. A: Estabilidad presupuestaria y consagración del freno constitucional al endeudamiento. Opus cit. P. 27. BAQUERO CRUZ, J. Entre competencia y libre circulación. El derecho constitucional económico de la Comunidad Europea. Edit. Civitas. Madrid 2002. Pp. 95 y ss. Pérez Tremps, P. Constitución española y comunidad europea. Edit. Civitas-Fundación Universidad-Empresa. Madrid 1994. Pp. 65 y ss. Alonso García, R. Derecho comunitario, Derechos Nacionales y Derecho Común Europeo. Edit. Civitas Madrid 1989. Pp. 88 y ss. De este último autor también puede consultarse El Juez Nacional en la Encrucijada Europea de los Derechos Fundamentales. Edit. Cuadernos Civitas. Madrid. 2014. También pueden verse las Declaraciones 1/1992, de 1 de julio y la 1/2004, de 13 de diciembre, del Tribunal Constitucional.

${ }^{28}$ MuÑoz Machado, S. La Unión Europea y las mutaciones del Estado. Edit. Alianza editorial 1993. Pp. 54 y ss. También se puede consultar esta tesis en su obra Vieja y nueva Constitución. Edit. Crítica. Barcelona 2016. P. 154.

29 Rubio Llorente, F. «El referéndum superfluo y el necesario». El País. 11 de julio de 2003. Recientemente, reafirmando su doctrina de las Declaraciones de 1992 y 2004 la STC 26/2014, de 13 de febrero, en relación con el Caso Melloni del TJUE. Sobre dicha asunto puede consultarse el trabajo de Punset Blanco, R. «Derechos fundamentales y primacía del derecho europeo antes y después de caso Melloni». En la Revista de Teoría y Realidad Constitucional. Núm. 39. 2017. Pp. 189-212. De Montalvo JäÄskeläinen, F. «El Tribunal de Justicia al 
Como ha señalado Embid Irujo, la crisis económica ha contribuido de forma notable a que se visualice el fenómeno de la incorporación de los Tratados de la Unión al proceso de constitucionalización de la economía ${ }^{30}$. Por lo tanto, aunque las Constituciones nacionales han regulado la respuesta a la crisis -estabilidad presupuestaria y limitación de la deuda-, ha sido el Derecho europeo el que ha marcado las condiciones de cómo se debía responder a la nueva situación económica $^{31}$. Propuesta política que aunque quedaba enunciada en el artículo 126 TFUE se mostró insuficiente para hacer frente a los problemas financieros por los que pasaron algunos países de la zona euro en los primeros años del siglo XXI y que requirió de importantes reformas normativa que se cierran con el Pacto de Estabilidad, Coordinación y Gobernanza (2012) ${ }^{32}$. Pero la Estabilidad financiera en la política europea tiene unos antecedentes mucho más remotos.

rescate de los derechos en el contexto de las medidas de estabilidad derivadas de la crisis económica: pringle v Ledra advertisins». En la Revista de Teoría y Realidad Constitucional. Núm. 39. 2017. Pp. 611-636.

30 Embid Irujo, A. «La constitucionalización de la crisis económica». En la obra de AA. VV. La Constitución económica. XVII Jornadas de la Asociación de Letrados del Tribunal Constitucional. Edit. Centro de Estudios Políticos y Constitucionales. Cuadernos y Debates 223. Madrid. 2012. P. 135-136.

31 Hasta tal punto ha sido así que como ha apuntado Pérez Tremps, nos encontramos que en la regulación constitucional de la estabilidad presupuestaria las remisiones que el artículo 135.2 y 3 hace al Derecho Europeo produce un efecto de desconstitucionalización y europeización de las materias allí señaladas, que convierten al Derecho Europeo directamente en canon o parámetro del juicio de constitucionalidad por remisión, frente a su consideración hasta abora, como mucho, de parámetro de interpretación. PERÉz Tremps, P. «La constitucionalización de la estabilidad presupuestaria y sus efectos». En la Conferencia desarrollada en el seminario «Protecting economic and social rights in times of economic crisis», celebrado en Ouro Preto (Brasil) los días 5 y 6 de mayo de 2014. Consultada por deferencia del autor.

32 Transcurrido el tiempo podemos analizar con cierta perspectiva y objetividad lo que aconteció en aquellos años, pero en esos momentos lo más significativo era la inmensidad de la crisis financiera y la incapacidad de los instrumentos políticos y normativos con los que contaba la UEM. Todo ello, generaba una enorme inestabilidad social y una fractura institucional que llevó a tomar medidas de «urgencia» donde primaba más la necesidad fáctica que la búsqueda del equilibrio y la racionalidad. Vid. BAÑo LEÓN, J. M. «Libre competencia y regulación económica en un mundo en crisis (una visión contemporánea de la soberanía en la Unión monetaria)». En la obra de AA. VV. La Constitución económica. XVII Jornadas de la Asociación de Letrados del Tribunal Constitucional. Edit. Centro de Estudios Políticos y Constitucionales. Cuadernos y Debates 223. Madrid. 2012. P. 227-245. ARANDA Álvarez, E. «Las razones europeas para la reforma constitucional en España». En la obra de AA. VV. La constitucionalización de la estabilidad presupuestaria. Directores Enrique Álvarez Conde y Clara Souto Galván. Edit. IDP y Universidad Rey Juan Carlos. Madrid. 2012. Pp. 203-226. 
Como es bien conocido, la idea de estabilidad presupuestaria aparece ya en los trabajos que se producen para la aprobación del mercado interior (Libro Blanco de la Comisión de $1985^{33}$ ) y el Acta Única Europea de $1986^{34}$, mediante la cual se sientan las bases para la coordinación de políticas económicas que vayan más allá de la política presupuestaria de los Estados. Después vendrá el Tratado de la Unión Europea - Maastricht, 1992 - que aprueba los criterios de disciplina presupuestaria y control europeo sobre los tipos de cambio y la política monetaria. Dicho Tratado da lugar en a la conocida «Sentencia Maastricht» del Tribunal Constitucional alemán de 12 de octubre de 1993 y en la que, además de ratificarse la adhesión de Alemania al Tratado de Maastricht, se reconoce la atribución de competencias en materia monetaria a la Unión dejando claro que dicha atribución es de la UE porque previamente ha sido ratificada por el Parlamento alemán. De lo que se deduce que una integración que fuera más allá de lo autorizado por el Parlamento alemán se consideraría inconstitucional. A Maastricht le sigue el Tratado de Amsterdam - 1997 — con la regulación del Pacto de Estabilidad y Crecimiento, que conlleva un sistema para el control de los déficits públicos excesivos supervisado por el Consejo Europeo (déficits no superiores al 3\% del PIB y tope de endeudamiento inferior al 60\% del PIB) ${ }^{35}$. Desde esa fecha hasta 2007, cuando se aprueban las reformas de los Tratados en Lisboa, el tiempo sigue transcurriendo con más cambios. El Consejo de Santa María de Feira en el 2000 tomó decisiones en política monetaria de mayor austeridad, lo que llevó tanto a la Unión como a los Estados a caer en un tiempo de duda y judicialización sobre los controles del déficit: incapacidad de imponer esos criterios a los excesos de déficit de Francia y Alemania y la retirada de los expedientes sancionadores por esos mismos motivos a Irlanda y Portugal (años 2001 a 2003). Situación toda ella que terminó con los acuerdos de la Comisión de 2005 que dieron lugar a los Reglamentos (CE) 1055/2005 del Consejo, de 27 de julio de 2005, Reglamento (CE) 1056/2005, del Consejo, de 27 de julio de 2005 que sirvieron para flexibilizar los criterios de déficit y deuda pública vigente hasta esa fecha.

33 «Commission White Paper to the European Council on Completion of the Internal Market». COM (85), of 14 june 1985.

34 El AUE se firma en Luxemburgo el 17 de febrero de 1986 por nueve Estados miembros. El 28 de febrero de 1986 se firma por Dinamarca, Italia y Grecia. Entra en vigor el 1 julio de 1987.

35 El Pacto de Estabilidad y Crecimiento, en su formulación inicial, constaba de una resolución del Consejo Europeo (adoptada en 1997) y dos reglamentos del Consejo, de 7 de julio de 1997 (Reglamento 1466/1997 y Reglamento 1467/1997), en los que se detallaban las modalidades técnicas (uno sobre la supervisión de las situaciones presupuestarias y la coordinación de las políticas económicas, y otro sobre la aplicación del procedimiento de déficit excesivo). 
Un nuevo e importante paso en esa política de estabilidad presupuestaria y control de la deuda pública se va a dar con el Tratado de Lisboa —2007— y, en particular, el Tratado de Funcionamiento de la Unión Europea (TFUE). El texto empieza reclamando la coordinación de las políticas económicas de los Estados de la Unión (art. 2.3.); la competencia exclusiva de la Unión sobre la política monetaria de los Estados que forman parte del euro (art. 3.1.); la necesidad de que se respete el principio de una economía de mercado abierta y de libre competencia (art. 120); la atribución al Consejo de la orientación de la política económica y su supervisión (art. 121); la capacidad de éste para dictar medidas de coordinación y supervisión económica y garantizar su vigencia (art. 136), en particular, evitando los déficits públicos excesivos y los excesos de deuda pública (art. 126). A estos preceptos hay que añadir el Protocolo (n. $\left.{ }^{\circ} 12\right)$ aplicable en caso de déficit excesivo, los Reglamentos del Pacto de Estabilidad y Crecimiento y el Código de Conducta para la implementación de los programas de estabilidad y convergencia ${ }^{36}$.

En los años siguientes, y hasta la actualidad, la crisis económica y fiscal que se inicia en 2008 hace que las instituciones europeas refuercen su intervención en la política económica de los Estados, especialmente, de la zona euro. Intervención que ha supuesto el aumento de los criterios de coordinación y gobernanza económica a disposición de los organismos de la Unión, en especial del Consejo de la Unión Europea, y la limitación de la capacidad de los Estados para aprobar con entera libertad sus Presupuestos y condicionar sus políticas públicas y sociales. Ese gobierno económico de la Unión Europea se articula sobre cuatro ejes: primero, el semestre europeo, aprobado por el Consejo de Ministros de Economía y Finanzas de la UE el 7 de septiembre de 2010 y que es un ciclo de coordinación de las políticas económicas y presupuestarias dentro de la UE. Abarca tres bloques de materias a coordinar, i) reforma estructurales dedicadas a promover el crecimiento y el empleo de conformidad con la Estrategia Europea 2020, ii) políticas presupuestarias para garantizar la sostenibilidad de la hacienda pública de conformidad con el Pacto de Estabilidad y Crecimiento y iii) prevención de desequilibrios macroeconómicos excesivos. Segundo, el Pacto por el Euro

36 Montalvo ha señalado que activada en Europa la crisis financiera iniciada en 2008 pronto se comprobó que los Tratados se mostraban excesivamente parcos en el ámbito económico y financiero de manera que no daban fundamento jurídico suficiente a la adopción de políticas de intervención económica y de ayuda, impidiendo prima facie una política económica común que permitiera solventar las turbulencias económicas y los problemas derivados del excesivo endeudamiento de los Estados miembros en una contexto en el que los mercados ya no ofrecían un acceso fácil a la financiación. DE MONTALVo JäÄsKeläInEN, F. «El Tribunal de Justicia al rescate de los derechos en el contexto de las medidas de estabilidad derivadas de la crisis... Opus cit. Pp. 614. 
plus que supone la reforma del artículo 136 del TFUE y el Mecanismo Europeo de Estabilidad. Fue aprobado en el Consejo Europeo del 24 y 25 de 2011 y suscrito por 23 países de la zona euro y otros seis que no forman parte de ésta (Bulgaria, Dinamarca, Letonia, Lituania, Polonia y Rumanía). Se centra en cuatro ámbitos de la política económica europea: competitividad, empleo, sostenibilidad de las finanzas públicas y reforzamiento de la estabilidad financiera. Sus compromisos fueron incorporados a los Programas Naciones de Reforma de los Estados miembros afectados. Tercero, el Pacto de Estabilidad y Crecimiento (Six Pack). Dicho Pacto fue aprobado por el Parlamento Europeo y refrendado por el Consejo, formado por cinco Reglamentos y una Directiva que entraron en vigor en septiembre de 2011. Incluye, entre otras medidas: la reforma del Pacto de Estabilidad y Crecimiento y la Directiva 2011/85 de marcos presupuestarios nacionales, que culminaron con la firma del Tratado de Estabilidad, Coordinación y Gobernanza en la Unión Económica y Monetaria, el 2 de marzo de 2012. Se organiza con dos objetivos: política económica de prevención, mediante la cual los Estados miembros deben presentar un programa anual de estabilidad o convergencia y un programa nacional de reformas para conseguir unas finanzas públicas saneadas a medio plazo; política económica de corrección, que implica que el Consejo, en el supuesto de que un Estado incumpla el déficit presupuestario del 3\% del Tratado, emite recomendaciones para solucionar el problema y si se incumplen esas recomendaciones, se pueden imponer sanciones. Cuarto, Pacto de Fortalecimiento del Sector Financiero, que entró en vigor en el 2011 y tiene como objetivo supervisar la actividad de los agentes financieros. Se organiza mediante una Junta Europea de Riesgos Sistémicos, responsable de velar porque los riesgos macroeconómicos se detecten en una fase suficientemente temprana y tres autoridades europeas de supervisión sectoriales: Autoridad Bancaria Europea (ABE), Autoridad Europea de Seguros y Pensiones de Jubilación (AESPJ) y Autoridad Europea de Valores y Mercados (AEVM) ${ }^{37}$.

A los efectos de lo que ahora nos interesa es importante señalar que el Tratado de Estabilidad, Coordinación y Gobernanza de la UE (TECG) recoge una cláusula que reclama a los Estados contratantes que, yendo más allá de las previsiones del artículo 126 TFUE y el Protocolo (n. ${ }^{\circ}$ 12), se comprometan a mantener una situación presupuestaria de sus administraciones públicas de equilibrio o superávit (art. 3 TECG). Además, se dice que las exigencias jurídicas de equilibrio o superávit deben incorporarse a sus ordenamientos jurídicos «mediante disposiciones que tengan

37 Un estudio detallado sobre la evolución de la gobernanza económica en la Unión Europea puede verse en el trabajo de BAR CEDón, A. «La reforma constitucional y la gobernanza económica de la Unión Europea». En la Revista Teoría y Realidad Constitucional. Núm. 30. 2012. Pp. 59-87. 
fuerza vinculante y sean de carácter permanente, preferentemente de rango constitucional o cuyo respeto y cumplimiento estén de otro modo plenamente garantizados a lo largo de los procedimientos presupuestarios nacionales» (art. 3.2. TECG). Para algunos autores esta declaración no solo reclama la regulación constitucional de la estabilidad presupuestaria por los Estados, sino que pretende evitar que aquéllos que ya lo han hecho den un paso atrás y hagan una reforma en sentido contrario.

Pero quizás, lo más importante a nuestros efectos no sea el iter político normativo que ha tenido la estabilidad presupuestaria sino los objetivos que con ella se persiguen. Desde el Tratado de Maastricht se empieza a constatar que la configuración del derecho económico europeo va a estar muy determinado por las políticas monetarias. Pese al Informe Delors, previo al Tratado y en el que se hacía mención expresa a que dicha política se tenía que organizar desarrollando de forma conjunta y paralela la unión económica y la unión monetaria ${ }^{38}$, el resultado fue, como ha señalado Ruíz Almendral, que se ha creado un «...modelo bibrido de gobernanza, donde la politica monetaria y la económica se encuentran totalmente escindidas y atribuidas a niveles de gobierno distintos, así como a una institución independiente como el BCE. Abora bien, mientras la politica monetaria se encuentra atribuida en bloque a la UE, a través de la Comisión europea y el BCE, la política económica está en manos de los Estados miembros, pero también con obligaciones de «derecho blando» (sofl law), que exigen su coordinación con el resto, y prevén una intensa intervención de la Comisión y el Consejo». Un paso más en ese modelo de predominio de las políticas monetarias es el Pacto de Estabilidad y Crecimiento que crea el BCE (1998) con el objetivo de coordinar las políticas económico-monetarias (v.gr. controlar la estabilidad de precios o los tipos de interés) ${ }^{39}$. Para mejorar el empleo, propone una desindexación salaria radical, flexibilización en los procesos de negociación colectiva y reducción de los niveles de protección social. Otmar Issing, economista jefe del Bundesbank y miembro del BCE (1996) decía «La unión social en el debate social europeo significa especialmente una armonización de los

38 El Informe Delors, aprobado por la Comisión Europea (1980) en el marco de la incipiente UEM, inspira el «modelo social europeo», con el que se pretendía que la Unión fuera más allá de la integración económica y tuviera un perfil social. Vid. BARón CRESPO, E. «Constitución y modelo social Europeo». En la Revista Estudios de Economía Aplicada. Vol. 27-3. Pp. 2009. Pp. 599-608. Casa BaAmonde, M. E. «El gobierno económico de la Unión Europea y el Estado social». En Reforma constitucional y estabilidad presupuestaria. El artículo 135 de la Constitución española. Cuadernos y Debates. Núm. 227. Dir. Diego López Garrido. Edit. Centro de Estudios Políticos y Constitucionales. Madrid. 2013. Pp. 235-286. Recientemente (26 de abril de 2017) se ha publicado el Documento de Reflexión sobre la Dimensión Social Europea por parte de la Comisión Europea en el que se pone en valor la el desarrollo de la Europa social. Vid. https:/ec.europa.eu/ commission/sites/beta-political/files/reflection-paper-social-dimension-europe_es.pdf.

39 Ruiz Almendral, V: Estabilidad presupuestaria y gasto público en España. Opus cit. Pp. 60-76. 
estándares sociales, y, lo que es más, al nivel más alto posible. La unión social requiere un gran número de regulaciones más estrictas del mercado de trabajo. La unión monetaria requiere lo contrario: una flexibilidad considerablemente mayor en el mercado de trabajo» ${ }^{40}$.

El último, aunque seguramente no definitivo, paso en esa regulación económica europea con claro perfil monetarista es el Pacto de Estabilidad, Coordinación y Gobernanza (Fiscal Compact). Con el TECG estamos ante un acuerdo intergubermanental ${ }^{41}$-no es una auténtica reforma del TFUE- que para mucha doctrina ha sido la consolidación definitiva de la Constitución económica europea con el que se pretende sobre todo garantizar que los Estados mantengan unas finanzas sostenibles y eviten un déficit excesivo, puesto que entiende que garantizar la estabilidad presupuestaria en la zona euro es vital ${ }^{42}$. Calvo ha dicho que es un Pacto al que el compromiso que le preocupa es el gasto público y se muestra inoperante sobre los ingresos y las medidas económicas concretas ${ }^{43}$. Por lo que, señala dicho autor, más que ante un pacto fiscal estamos ante un compromiso presupuestario que refuerza las políticas europeas de austeridad. El resultado final con esta legislación europea a favor de la disciplina presupuestaria y la limitación de la capacidad de endeudamiento es que el margen de actuación para el derecho constitucional económico nacional es francamente reducido. Se limita la capacidad de actuación en el plano financiero tanto del Gobierno como del Parlamento ${ }^{44} \mathrm{y}$, lo que es más grave, se genera la necesidad de realizar reformas que están restringiendo el Estado del bienestar.

Aunque no les falta razón a aquéllos que entienden que este derecho constitucional económico europeo de perfiles fuertemente monetaristas se ha extendi-

40 Issig, O. «Europa en el camino hacia la Unión Monetaria». Perspectivas del Sistema Financiero. Núm. 58. Madrid 1997. P. 40. En la misma línea Mundell, R. «El futuro del euro: una expectativa favorable». En la Revista Política Exterior. Núm. 63. Madrid 1998.

41 En este sentido puede verse el trabajo de Martín y PÉrez de NANCLAREs, J. «El nuevo Tratado de Estabilidad Coordinación y Gobernanza de la UEM: reflexiones a propósito de una peculiar reforma realizada fuera de los Tratados Constitutivos». En la Revista de Derecho Comunitario Europeo. Núm. 42, 2012. Pp. 397-491.

42 García Roca, J. y Martínez Lago, M. A: Estabilidad presupuestaria y consagración del freno constitucional al endeudamiento. Opus cit. P. 57.

43 Garcia Calvo, R. El Pacto Fiscal Europeo. Edit. Civitas, Madrid 2013. Pp. 51-52.

44 Sobre la pérdida de centralidad del Parlamento en la tramitación de los presupuestos vid. Martínez Lago, M.Á. «Constitucionalización del principio de estabilidad presupuestaria en la Unión Europea y en España. La Ley Orgánica de Estabilidad Presupuestaria y Sostenibilidad Financiera». En Reforma constitucional y estabilidad presupuestaria. El artículo 135 de la Constitución española. Cuadernos y Debates. Núm. 227. Dir. Diego López Garrido. Edit. Centro de Estudios Políticos y Constitucionales. Madrid. 2013. Pp. 155-157. 
do en la eurozona y limita los ámbitos económico y fiscal de actuación de los Estados, — tal es así, que hasta recomienda que sus mandatos se lleven a las Constituciones de los Estados-, lo cierto es que, en tanto que incide en el modelo de Estado social y en muchos de los derechos que éste lleva implícitos, requiere algún cuestionamiento que pretendemos hacer en las próximas páginas.

\section{LA TENSIÓN ENTRE LOS DERECHOS ECONÓMICOS Y SOCIALES Y LA ESTABILIDAD PRESUPUESTARIA}

La estabilidad presupuestaria, como límite al déficit y endeudamiento excesivos no es un principio que por definición haya de considerarse negativo. Que las Administraciones Públicas ajusten su gasto y la solicitud de recursos a cuenta de acuerdo con sus capacidades para poder hacerles frente y que lo hagan en el contexto de los objetivos políticos y sociales que el modelo de Estado busca, parece razonable. De hecho un déficit y una deuda desbocados son, con seguridad, la situación más grave para el interés general y la continuidad del Estado ${ }^{45}$.

Por otro lado, la preservación de los derechos económicos y sociales no solo es razonable sino que ha de formar parte de los criterios de actuación de las administraciones públicas en un Estado social que reclama a los poderes públicos promover las condiciones para que la libertad y la igualdad del individuo y de los grupos en que se integra sean reales y efectivas (art. 9.2 CE) ${ }^{46}$.

Por eso, como en tantas otras ocasiones, la cuestión aquí es que se deben hacer compatible intereses que pueden parecer contrapuestos: el principio de estabilidad presupuestaria y la necesidad de pervivencia del modelo de Estado y lo que éste conlleva en cuanto a la preservación de la igualdad, la solidaridad y los derechos sociales ${ }^{47}$. El problema es saber si el mandato de estabilidad presupues-

45 Vid. por todos, Bayona de Perogordo, J. J. y Soler Roch, M. T. Compendio de Derecho Financiero, opus cit. Pp. 165 y ss. Martín Queralt, J. M; Lozano Serrano, C.; Tejerizo López, J. M. y Casado Ollero, G. Curso de Derecho Financiero y Tributario. Edit. Tecnos. Vigésima Sexta Edición. Madrid 2015. Pp. 824 y ss.

46 Zornoza Pérez, J. Hacienda pública, gasto público y derechos económicos y sociales. Opus cit. P. 26.

47 Como dijera Böckenförde, el problema que se plantea con la ampliación de la actividad social del Estado es el de la consiguiente dependencia del Estado respecto de una economía expansiva, cuy a aportación (creciente) se hace imprescindible con el fin de obtener los recursos necesarios para la realización de la tareas de garantía del Estado social...». BöCKENFÖRDE, E. W. Estudios sobre el Estado de Derecho y la democracia. Edit. Trotta. Madrid 2000. P. 130. CorTI, H. «Ley de Presupuestos y Derechos fundamentales: los fundamentos de un nuevo paradigma jurídico-financiero». En la Revista Jurídica de Buenos Aires. Tomo I. 2010. Pp. 657 y ss. Holmes, ST y Sunstein, C. El costo de los derechos. Por qué la libertad depende de los impuestos. Edit. Siglo veintiuno. Buenos Aires 2011. Pp. 241-252. Burgaya, J. El Estado de bienestar y sus detractores. A propósito de los orígenes y la encrucijada del mode- 
taria recogido en el derecho de la UE se puede aunar con el Estado social o, por el contrario, lo que hace es apuntarse a un modelo de economía liberal que pudiera entrar en colisión con el marco constitucional español. En este sentido, sin darle más importancia que la de una opinión doctrinal más, aunque bien significativa, queremos hacernos eco de las palabras del profesor Paul Kirchhof, catedrático de Derecho Público, Financiero y Tributario de la Universidad de Heidelberg y ex Magistrado del Tribunal Constitucional alemán, que decía que «los Estados y las sociedades europeos se han ido acostumbrado a vivir por encima de sus posibilidades. El Estado en libertad se financia no con sus propiedades y empresas públicas, sino mediante la participación en el éxito económico privado. El Estado en libertad garantiza libertad profesional y derecho a la propiedad privada, confía a la iniciativa privada los factores de la producción trabajo y capital; por tal razón, se ve obligado a financiarse mediante impuestos al trabajo y el capital» ${ }^{48}$. Es difícil encontrar una declaración más clara y directa de cómo se entendía, en particular en centro Europa, el Estado del Bienestar y los que deberían ser los objetivos económicos del Estado: Europa ha vivido «por encima de sus posibilidades» y el Estado lo que ha de hacer económicamente es preservar la libertad contractual y el derecho de propiedad para que los agentes económicos determinen las condiciones de producción y generación de riqueza. Interpretación que, como decíamos, tiene una larga tradición en la cultura económica alemana. Recordemos que ya en el artículo 87 de la Constitución de Weimar (1919) se decía que «no se puede recurrir al empréstito sino en caso de necesidades extraordinaria y, por regla general, únicamente para gastos de fines productivos. Los empréstitos, lo mismo que toda prestación de seguridad encargada al Reich, deben ser autorizados por una ley del Reich». El argumento para fundamentar esta cultura de limitación del gasto público y la reducción de la deuda era que no se debía financiar el progreso de hoy con obligaciones para las generaciones futuras. Las sociedades que viven a crédito manifiestan un comportamiento altamente insolidario con sus hijos y generan peligros para la estabilidad del país a medio y largo plazo. Es un planteamiento presupuestario que trae causa en la tradición liberal del xix que entendía que una buena economía

lo social europeo en tiempos de crisis. Barcelona. Edit. Octaedro. 2013. Häвerle, P. Pluralismo y Constitución. Estudios de Teoría Constitucional y de la sociedad abierta. Edit. Tecnos. Madrid. 2002. P. 213. Aranda Álvarez, E. «Repensando los derechos económicos, sociales y culturales». En la obra de AA. VV. Los restos del Estado y la Administración en el siglo XXI. Libro Homenaje al profesor Tomás de la Quadra-Salcedo Fernández del Castillo. Coordinadores Luciano Parejo Alfonso y José Vida Fernández. Tomo II. Pp. 1335-1338.

${ }^{48}$ Kirchiof, P. «La constitucionalización de la deuda soberana. Un diálogo con Antonio López Pina». En Revista de Teoría y Realidad Constitucional. Núm. 29, 2012. P. 78. 
pública era aquélla que garantizaba el equilibrio presupuestario o, incluso, el superávit en las cuentas de las administraciones públicas ${ }^{49}$.

De ser así, y si la estabilidad presupuestaria que ofrece el «nuevo» derecho europeo responde a esquemas económicos del neoliberalismo, la pregunta inmediata que surge es si es posible que dicho derecho pueda introducir este tipo de cambios en el derecho constitucional de los Estados y si el artículo 135 CE incorporado por mandato de esa estabilidad presupuestaria no se debería interpretar de conformidad al Estado social y la preservación de los derechos económicos y sociales ${ }^{50}$.

La declaración de intenciones expresada en la Exposición de Motivos de la reforma constitucional de 27 de septiembre de 2011 no nos lleva por el camino de la integración de bienes e interpretación sistemática de interés, más bien al contrario: la estabilidad presupuestaria adquiere un valor verdaderamente estructural y condicionante de la capacidad de actuación del Estado, del mantenimiento y desarrollo del Estado Social que proclama el artículo 1.1 de la propia Ley Fundamental y, en definitiva, de la prosperidad presente y futura de los ciudadanos. Un valor, pues, que justifica su consagración constitucional, con el efecto de limitar y orientar, con el mayor rango normativo, la actuación de los poderes públicos. Dicha forma de ver la estabilidad presupuestaria, como ya se ha señalado, entraría con toda seguridad en colisión con los principios más elementales del Estado social y la preservación de los derechos que lo hacen efectivo. Por ello, desde nuestro punto de vista, ésta no puede ser la interpretación que se ha de hacer del artículo 135 de la CE. Los principios de coherencia y sistematicidad del ordenamiento nos han de llevar a una interpretación del precepto de conformidad con el resto de las normas constitucionales. Una interpretación que sea conforme con el modelo de Estado y los contenidos materiales de la Constitución ${ }^{51}$.

49 Alguno de esos autores representantes del liberalismo o neoliberalismo ya los citamos al inicio de este trabajo. Vid. cita núm. 1. También pueden verse a LASKI, H. J. El liberalismo Europeo. Edit. Fondo de Cultura Económica. Decimotercera reimpresión. México 1990. Entre las propuestas neoliberales recientes vid. Mickkethwait, J. y Wooldridge, A. La cuarta revolución. La carrera global para reinventar el Estado. Edit. Galaxia Gutenberg. Madrid. 2015.

50 No se ha de perder de vista también que el artículo 135.4 CE dice que Los límites de déficit estructural y de volumen de deuda pública solo podrán superarse en caso de catástrofes naturales, recesión económica o situaciones de emergencia extraordinaria que escapen al control del Estado y perjudiquen considerablemente la situación financiera o la sostenibilidad económica o social del Estado, apreciadas por la mayoría absoluta de los miembros del Congreso de los Diputados.

51 Estoy de acuerdo con Menéndez Sebastián cuando dice que la estabilidad presupuestaria no puede servir, en ningún caso, de excusa para atacar al Estado Social, que, por otra parte, no solo, como se ha visto, es otro mandato de la CE, de igual modo que las previsiones del citado artículo 135, sino que es además un objetivo de la misma, que prevalece por efecto del propio párrafo cuarto de dicho precepto». MENÉNDEZ SABASTÍAN, E. M. «La configuración constitucional del Estado Social y sus implicaciones en época de crisis». En la obra de AA. VV. Memorial para la reforma del Estado. Estudio en homenaje al 
Pues bien, para situar en sus justos términos la importancia de los derechos económicos y sociales en el Estado social y democrático de Derecho hay que empezar recordando que en la regulación in extenso de los derechos fundamentales constitucionalizados - Título I- el Texto Fundamental distingue entre unos y otros no desde un punto de vista material o sistemático, sino desde la protección que les asegura en el artículo 53 CE: máxima protección para los derechos y deberes de la Sección 1. a del Capítulo II, junto con la igualdad del 14 CE y la objeción de conciencia del 30.2 CE. Para los de la Sección 2. ${ }^{a}$, también de ese capítulo, una protección similar a los anteriores en la vinculatoriedad, reserva de ley y contenido esencial, aunque una menor protección jurisdiccional. Por su parte, la protección es más limitada respecto de los principios rectores del Capítulo III. Se dice que «informarán la legislación positiva, la práctica judicial y la actuación de los poderes públicos» $\mathrm{y}$ «solo podrán ser alegados ante la jurisdicción ordinaria de acuerdo con lo que dispongan las leyes que los desarrollen» (53.3 CE). Es decir, lo que salta a la vista de este apartado tercero del artículo 53 es que los principios rectores no generan derechos subjetivos ejercitables ante los tribunales. Pero, desde luego, no se puede entender que el valor de esos derechos sea retórico o meramente programático: no se debe olvidar la normatividad de todo el texto constitucional —art. 9.1 CE- Dichos principios rectores transcienden la consideración de normas programáticas y, como se ha adelantado, aunque no son derechos subjetivos sí implicarían las condiciones necesarias para su aparición ${ }^{52}$.

Otra cuestión que hemos de tener en cuenta al hacer referencia a los derechos económicos y sociales es que algunos de ellos se encuentran entre los de mayor nivel de protección — art. 27 CE, derecho a la educación y art. $28 \mathrm{CE}$, derecho de huelga y libre sindicación_; otros de protección intermedia — art. 35, derecho al trabajo y derechos laborales, art. 36, derecho adoptar medidas de conflicto colectivo-; y, finalmente, el grueso de ellos integrados entre los principios rectores de la política social y económica.

Sobre estos últimos, como decíamos, lo primero que hay que hacer es entender en sus justos términos la previsión del artículo 53.3 CE y, en particular, cuando dice que dichos principios «informarán la legislación positiva, la práctica judicial y la actuación de los poderes públicos». De este enunciado se desprende con toda claridad la vinculatoriedad de los principios rectores para los tres poderes

profesor Santiago Muños Machado. Tomo I. Coord. José M. ${ }^{a}$ Baño León. Edit. Centro de Estudios Políticos y Constitucionales. Madrid 2016. P. 429.

52 García Macho, R. «El deterioro creciente del Estado social y derechos sociales en España». En la obra de AA. VV. Los restos del Estado y la Administración en el siglo XXI. Libro Homenaje al profesor Tomás de la Quadra-Salcedo Fernández del Castillo. Coordinadores Luciano Parejo Alfonso y José Vida Fernández. Tomo II. Pp.1308-1323. 
del Estado. Es cierto que los ciudadanos no pueden invocarlos directamente ante los tribunales y ello les resta eficacia, pero ello no resta un ápice de vinculatoriedad para el legislador, los tribunales y la actuación del día a día de las administraciones públicas. Es decir, con los principios rectores no estamos ante meras declaraciones programáticas sino ante auténticas obligaciones constitucionales y, por lo tanto, aunque las condiciones económicas siempre pueden aparecer como un factor condicionante para su efectividad, no cabe la menor duda de que eso no les hace menos relevantes constitucionalmente hablando ${ }^{53}$.

Una segunda cuestión que tenemos que tener en cuenta respecto de los principios rectores es la ausencia expresa en el artículo 53.3 CE a que cuenten con un contenido esencial. Sobre este tema se ha pronunciado la doctrina, con no poco apoyo jurisprudencial ${ }^{54}$, para señalar que negar la existencia de un contenido esencial de los principios rectores del Capítulo III tiene poco sentido si se tiene en cuenta que estamos hablando de preceptos de una Constitución normativa. Si todos y cada uno de los artículos de la Constitución tienen valor normativo y vinculan a todos los poderes públicos (art. 9.1 CE) queda descartado que podamos situarnos ante los principios rectores como enunciados programáticos y, por el contrario, aunque el artículo 53.1. CE solo hable de contenido de los derechos del Capítulo II, en la práctica hay que asumir que los principios del Capítulo III y, más aún, todos y cada uno de los preceptos constitucionales, cuentan con dicho contenido esencial mínimo. Como ha señalado De la QuadraSalcedo «todos los días el Tribunal Constitucional está diciendo cual es el contenido esencial de cualquier precepto constitucional» 55 .

53 SALAS SÁNCHEZ, P. «La garantía de los derechos económicos y sociales y su efectividad en situaciones de crisis económica». En la Revista Española de Control Externo. Vol. 16. Núm. 46. 2014. Pp. 11-142. Cascajo Castro, J. L. «Derechos sociales». En la obra de AA. VV. Derechos Sociales y Principio Rectores. Actas del IX Congreso de la Asociación de Constitucionalista de España. Coordinadores: José Luis Cascajo Castro, Manuel Terol Becerra, Antonio Domínguez Vila y Vicente Navarro Marchante. Edit. Tirant lo Blanch. Valencia. 2012. Pp. 19-44. Los principios rectores de la politica social y económica. Director Javier Tajadura. Edit. Biblioteca Nueva. Madrid 2004. Tratado sobre protección de derechos sociales. Directores Manuel Terol Becerra y Luis Jimnena Quesada. Edit. Tirant lo Blanch. Valencia 2014. Lecciones sobre estado social y derechos sociales. Dirige Algert Noguera Fernández. Edit. Tirant lo Blanch. Valencia 2014. García Schwarz, R. Derechos Sociales: Imprescindibilidad y Garantías. Edit. Thomson Reuters. Navarra 2011.

54 Especial interés tiene el ATC 239/2012, sobre el RDL 16/2012, de 20 de abril, de medidas urgentes para garantizar la sostenibilidad del Sistema Nacional de Salud.

55 Quadra-Salcedo Fernández del Castillo, T: Derecho Público tras la crisis económica en el Estado social y democrático. Opus cit. P. 102. También en MenÉndez SABAstían, E. M. La configuración constitucional del Estado Social y sus implicaciones en época de crisis. Opus cit. P. 433. 
Luego si estamos de acuerdo en que los derechos económicos y sociales informan la actuación de los poderes públicos y cuentan, por estar recogidos constitucionalmente, con un «contenido esencial», tenemos que estar también de acuerdo con que su implementación respecto de las políticas anticrisis de reducción del gasto y recortes presupuestarios, es decir, de aplicación del principio de estabilidad presupuestaria, se ha de hacer de conformidad con criterios de proporcionalidad y respeto al pluralismo político. Como ya se ha señalado en páginas anteriores, el derecho de la UE también cuenta con límites cuando se sitúa en estos niveles de colisión con elementos identitarios de los Estados - reconocimiento de la identidad nacional (art. 4.2 TUE) — mediante los cuales los Tribunales Constitucionales han desarrollado una jurisprudencia sobre la identidad constitucional y el control de los ultra vires —en la jurisprudencia del Tribunal Constitucional alemán, desde las Sentencias Solange I y Solange II hasta la Sentencia sobre el Tratado de Lisboa, pasando por las Sentencias Bananas y sobre el Tratado de Maastricht- En esa línea, el Tribunal Constitucional español —Declaración 1/2004_, refiriéndose al contenido material del artículo 93 CE a los efectos del reconocimiento de la cesión de competencias derivadas de la Constitución a una institución internacional mediante tratados, señaló que existen límites implícitos a la atribución de competencia «que se traducen en el respeto de la soberanía del Estado, de nuestras estructuras constitucionales básicas y del sistema de valores y principios fundamentales consagrados en nuestra Constitución, en el que los derechos fundamentales adquieren sustantividad propia». Desde nuestro punto de vista, la cuestión que se está tratando — compatibilidad entre Estado social y estabilidad presupuestaria - se debería resolver sin llegar a este extremo, por lo que supone de poner en cuestión el proceso de conformación de una comunidad jurídica europea ${ }^{56}$. Precisamente por ello, se necesita por parte de todos, instituciones estatales y de la Unión, un esfuerzo de ajuste de esas políticas financieras que no nos lleven hasta ese punto de tensión con los fundamentos de los Estados.

Aplicar la normativa europea o nacional de estabilidad presupuestaria con criterios estrictamente monetaristas, sin tener en cuenta los efectos sobre las polí-

56 Sobre los controles constitucionales y unidad jurídica europea, en particular la tensión entre el Tribunal Constitucional alemán y el TJUE pueden consultarse: WENDEL, M. «El Tribunal Constitucional Federal Alemán entre protección jurídica y exceso competencial. Sobre la eficacia de los controles constitucionales nacionales en tiempos de crisis Europea». En la Revista Teoría y Realidad Constitucional. Núm. 39, 2017. Pp. 123-162. Martín y Pérez de Nanclares, J. M. «Órdago del Tribunal Constitucional alemán al proceso de integración europea (algo más que una sentencia crítica con el Tratado de Lisboa). En la Revista d'estudis autonòmics i federals. Pp. 97-145. VossKuHLe, A. «La integración Europea a través del Derecho». La contribución del Tribunal Constitucional Federal (Alemán). En la Revista Teoría y Realidad Constitucional. Núm. 39, 2017. Pp. 103-121. 
ticas públicas que desarrollan los derechos, podría considerarse una opción contraria a la Constitución ante la cual no sería descartable la posibilidad de recurso o cuestión de constitucionalidad ${ }^{57}$. Como ha señalado Quadra-Salcedo, es cierto que la aplicación del principio de proporcionalidad en un contexto de crisis económica, donde es normal que se reduzcan los ingresos del Estado y aumente el gasto público, requiere de una política de austeridad. Pero en tanto que esa política de recortes puede afectar a los servicios públicos y los derechos económicos y sociales, lo lógico es que se aplique con criterios de ponderación de intereses. Para ello, nada mejor que los criterios interpretativos del principio de proporcionalidad: i) fin lícito y justificado de la medida restrictiva; ii) que dicha medida de restricción sea adecuada al objetivo perseguido; iii) que no se cuente con otra medida restrictiva de derechos susceptible de producir los mismos efectos iv) comprobar que el objeto que se persigue con la restricción o supresión es de mayor valor o relevancia constitucional que los derechos sociales que se sacrifican.

\section{CONCLUSIONES}

Tanto el pacto europeo por la estabilidad como el constitucionalizado en el artículo 135 de la Constitución española responden a una voluntad confesa de que el Derecho presupuestario tenía que romper con la tradicional discrecionalidad política y ajustarse a la evolución de la economía. La estabilidad presupues-

57 De hecho algunas normas que durante estos años se han aprobado para hacer efectivos los principios de estabilidad presupuestaria han sido objeto de conocimiento del Tribunal Constitucional (vid. SSTC 8/2015, de 8 de enero y la 26/2016, de 18 de febrero). Las reformas legales en este sentido que, para muchos, han limitado, precarizado o impedido el ejercicio de derechos sociales reconocidos en distintos sectores sociales son: Mercado laboral, con la aprobación del Decreto-ley 3/2012, de 10 de febrero, de medidas urgentes para la reforma del mercado laboral (posteriormente transformado en Ley 3/2012, de 6 de julio). Dependencia, con la aprobación de Real Decreto-ley 8/2010, de 20 de mayo, por el que se adoptan medidas extraordinarias para la reducción del déficit público, el Real Decreto-ley 20/2011, de 30 de diciembre, de medidas urgentes en materia presupuestaria, tributaria y financiera para la corrección del déficit público, la Ley 2/2012, de 29 de junio, de Presupuestos generales del Estado para el año 2012 y el Real Decreto-ley 20/2012, de 13 de julio, de medidas para garantizar la estabilidad presupuestaria y de fomento de la competitividad. Educación, con el Real Decreto-ley 14/2012, de 20 de abril, de medidas urgentes de racionalización del gasto público en el ámbito educativo. Pensiones, con la Ley 23/2013, de racionalización y sostenibilidad del sistema de pensiones. Sanidad, con Real Decreto-ley 4/2010, de 26 de marzo, de racionalización del gasto farmacéutico con cargo al Sistema Nacional de Salud; Real Decreto-ley 9/2011, de 19 de agosto, de medidas para la mejora de la calidad y cohesión del sistema nacional de salud, de contribución a la consolidación fiscal, y de elevación del importe máximo de los avales del Estado para 2011 y el Real Decreto-Ley 16/2012 sobre el copago farmacéutico en el número de recetas y en el gasto farmacéutico.

N. ${ }^{\circ} 100$, septiembre-diciembre 2017, págs 881-914 
taria, la sostenibilidad financiera, el techo de gasto, la regla de oro o el déficit estructural excesivo se han convertido en los tótem de la nueva economía. Pareciera que solo el cálculo matemático que lleva a determinar cuándo se cumplen esas reglas es suficiente para asegurarnos el buen funcionamiento de la Unión, de los Estados y cerrar el paso a cualquier crisis económico financiera como la vivida. La realidad es que esa economía envuelta en cifras esconde también ideología. Un modelo económico que prioriza los resultados contables sobre las necesidades reales de los ciudadanos. Un modelo que da prioridad absoluta a las relaciones financieras —v.gr. pago de la deuda, objetivos de déficit— sobre las políticas sociales y los derechos que implican — - v.gr. derecho social europeo-. Una nueva gobernanza económica que, tras la supuesta objetividad de los protocolos macroeconómicos, establece unos criterios de responsabilidad presupuestaria de los Estados que solo son formalmente comunes puesto que es imposible tratar de forma igual lo que es diferente, que es lo que pasa entre las economías de los países del sur y de centro Europa.

Esta realidad, que se abre paso en la política y el Derecho, supone notables cambios respecto de la economía social de mercado que con tanto esfuerzo y tesón han construido las Constituciones contemporáneas europeas a lo largo de los últimos sesenta años. Seguramente, muchas de las decisiones políticas y de las normas que se han aprobado en estos años y que han llevado a esta transmutación, tienen que ver con una situación de emergencia, de extraordinaria y urgente necesidad. Pero ahora, estabilizada la economía mundial y, en particular de la UE, sería bueno que empezásemos a reajustar nuestro modelo económico financiero. La estabilidad presupuestaria y la sostenibilidad financiera son objetivos de gestión de los recursos públicos recomendables siempre que no se hagan efectivos a costa de poner en cuestión el modelo del Estado social y las condiciones mínimas de vida de las personas que éste pretende asegurar ${ }^{58}$. En consecuencia, ahora es el momento de buscar una interpretación que haga compatible la estabilidad presupuestaria y el control del déficit estructural con el mantenimiento de los derechos sociales y de los objetivos que han guiado durante las últimas décadas al Estado social y democrático de Derecho. Es lo que ha pretendido presentar el trabajo que ahora concluye.

58 En el ámbito de la UEM, el Documento de Reflexión sobre la profundización de la Unión Económica y monetaria, recientemente aprobado, podría ser un buen punto de arranque ya que reconoce que la Unión Económica y Monetaria sigue siendo insuficiente (...) porque todavía no ha sido capaz de corregir suficientemente las disparidades sociales y económicas que la crisis generó entre los miembros de la zona del euro y dentro de cada uno de estos países. Comisión Europea. Bruselas, 31.5.2017 COM (2017) 291 final. 
Title

Constitutional economic Law: Budget stability and Social rights.

Summary:

Introduction 1. Constitutional economic rules in the Spanish Constitution of 1978: the lack of a definite economic model and the diffuse reference to budget stability 2. Public spending as a key instrument in welfare state economic policies. 3. Justice principles regarding public spending contained in article 31.2 of the Spanish Constitution. 3. Budget stability in european law. evolution and goals. 4 . The tense balance between economic and social rights and budget stability. Conclusions.

\title{
Resumen:
}

La estabilidad presupuestaria y los límites a la deuda pública se han convertido en los principios referenciales de la política económica de la Unión Europea tras el paso por la crisis económica de los últimos años. La aplicación de estos principios supone hacer grandes recortes en el Estado del Bienestar que puede afectar sustancialmente a los derechos sociales e, incluso, el modelo de Estado de nuestro país. El presente artículo pretende dejar constancia que tanto la interpretación de esos principios como el nuevo artículo 135 de la CE deben ser interpretados de conformidad con las reglas económicas constitucionales que aseguran la vigencia del Estado social y democrático de Derecho.

\begin{abstract}
:
Budget stability and public debt limits have become key economic policy factors in the European Union in the wake of the recent economic crisis. The application of these principles involves major cuts to the Welfare State that may substantially affect social rights and even the model of State in our country. This article argues that both these principles and the new article 135 of the Spanish Constitution must be interpreted in accordance with constitutional economic rules that ensure the continuing validity of the social and democratic State based on the rule of law.
\end{abstract}

\section{Palabras claves:}

Constitución económica. Estabilidad presupuestaria. Límites a la deuda pública. Estado del Bienestar. Derechos sociales. 
Key words:

Economic constitution, budget stability, public debt limits, Welfare State, social rights. 